Sousa, R.G,; Santos, M.L. Percepção ambiental dos usuários da Fazenda Santa Branca Ecoturismo (APA - Ribeirão João Leite), Teresópolis (GO). Revista Brasileira de Ecoturismo, São Paulo, v.3, n.3, 2010, pp.460-477.

\title{
Percepção ambiental dos usuários da Fazenda Santa Branca Ecoturismo (APA - Ribeirão João Leite), Teresópolis (GO)
}

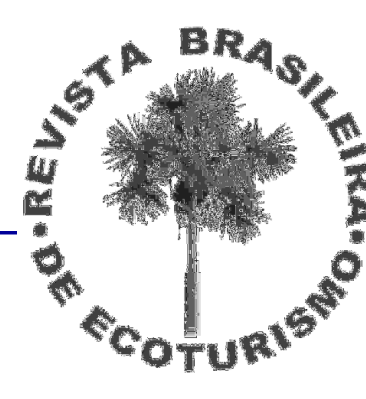

\author{
Raquel Gonçalves de Sousa, Mirley Luciene dos Santos
}

\section{RESUMO}

Os estudos na área da Percepção Ambiental despontam como ferramentas de grande importância para a elaboração de novas metodologias de Educação Ambiental (EA) e avaliação constante de trabalhos já implantados em Unidades de conservação. Frente a isso, o objetivo do trabalho foi inferir as diferentes posturas comportamentais dos usuários da Fazenda Santa Branca, em Teresópolis-GO, em relação ao ambiente natural e ao trabalho de educação ambiental realizado na fazenda, com base na aquisição e análise de informações de seu estado cognitivo. As concepções foram obtidas por meio de questionários e divididas em categorias como Antropocêntrica, Globalizante ou Naturalista (Reigota, 1991). O cruzamento das variáveis evidenciou que a concepção de meio ambiente independe dos grupos de usuários $\left(X^{2}=4,9, G . L .=6, p=1 \%\right)$, portanto não existe uma dependência entre ter uma concepção globalizante e ter participado das atividades de EA ou ser um funcionário, o que detecta faIhas na abordagem ambiental. Foi detectado ainda que as concepções de meio ambiente independem da escolaridade $\left(X^{2}=7,6, G . L .=9, p=1 \%\right)$, o que sugere falhas também nos níveis formais de ensino. A Educação Ambiental em nível Não-Formal deve seguir algumas orientações básicas, com atenção na abordagem das temáticas ambientais buscando sempre uma visão crítica, capaz de despertar para concepções globalizantes.

PALAVRAS-CHAVE: Meio Ambiente; Ecoturismo; Educação Ambiental.

\section{Environmental perception of users of Fazenda Santa Branca Ecoturismo (APA - Ribeirão João Leite), Teresópolis, GO, Brazil.}

\section{ABSTRACT}

Studies in the area of environmental perception emerge as tools of big importance to the preparation of the new methodology of environmental education in the on-going assessment of the work already implanted in Conservation Units. Taking this into account, the objective of this work was to infer the different behaviors of the users of Fazenda Santa Branca, in Teresópolis -GO, Brazil, related to the natural environment and the environmental education work carried out on the farm, based on the acquisition and analysis of the information of their cognitive state. The conceptions were obtained through questionnaires and divided into categories such as Anthrocentric, Globalizing or Naturalist (Reigota, 1991). The crossings of variables showed that the conception of what environment is does not depend on groups of users $(X 2=4,9, G . L .=6, p=1 \%)$, therefore there is not a dependence between having a globalizing conception and having participated in activities of environmental education or even being an employee, what detects flaws in the environmental approach. It was still detected the conceptions of environment are independent of the level of education $(X 2=7,6$, G.L. $=9, p=1 \%$ ), which also shows failures in the levels of formal education. The environmental education in a Non-Formal level should follow some basic guidelines, with attention to the approach of the environment themes always seeking a critical view, able to raise global conceptions.

KEYWORDS: Environmental; Ecotourism; Environmental Education. 
Percepção ambiental dos usuários da fazenda Santa Branca Ecoturismo (APA - Ribeirão João Leite, GO).

\section{Introdução}

A real situação ambiental e social em que o Brasil se encontra, remete ao seu histórico ambiental, já que simbolicamente, o nascimento e a constituição do país se deram sob o signo de um grande projeto de exploração econômica. Esse modelo se mostrou propício à formação de uma mentalidade predatória que transpõe gerações (WWF BRASIL, 2000).

O processo de desenvolvimento econômico, principalmente na cultura ocidental, continuou colaborando com esse sistema dominante de degradação ambiental, cujo desrespeito ao meio ambiente é resultado da ideologia que se desenvolveu com base na abundância de recursos naturais existentes e na falsa idéia de serem eles ilimitados (LUCION et al., 2006).

Este cenário de tradição histórico-predatória, mesmo com a aquisição de conhecimentos ecológicos durante os séculos decorrentes, urge por uma Educação Ambiental (EA) bem engajada. Um importante passo dado nessa direção foi à construção do "Tratado de Educação Ambiental para Sociedades Sustentáveis e Responsabilidade Global (TEASS)" documento criado pela sociedade civil durante a "Conferência das Nações Unidas sobre o Meio Ambiente e Desenvolvimento" realizada no Rio de Janeiro em 1992. O documento dispõe de princípios e diretrizes para o desenvolvimento de trabalhos com a temática Meio Ambiente e ao se unir aos pressupostos pedagógicos de Tbilisi (1977, marco histórico na emergência de políticas ambientais em todo o mundo) funciona como o fundamento pedagógico para a prática da EA. A EA no Brasil conta ainda com o Programa Nacional de Educação Ambiental (ProNEA), o qual tem por base a Educação para Sociedades Sustentáveis (PEDRINI; BRITO, 2006).

No que tange à legislação, a EA já havia sido mencionada no Decreto Legislativo Federal n. ${ }^{\circ} 3$ de 13 de fevereiro de 1948, e a Constituição Brasileira de 1988 trouxe pela primeira vez, um capítulo que trata do Meio Ambiente, o qual se encontra dissociado do capítulo que aborda a Educação Formal. Posteriormente, a Lei n. 9.795, de 27 de abril de 1999 veio instituir a Política Nacional de Educação Ambiental, trazendo em seu Art. 1. o conceito de Educação Ambiental (EA), como sendo:

[...] os processos por meio dos quais o indivíduo e a coletividade constroem valores sociais, conhecimentos, habilidades, atitudes e competências voltadas para a conservação do meio ambiente, bem de uso comum do povo, essencial à sadia qualidade de vida e sua sustentabilidade (BRASIL, 1999, p. 1).

A EA pode trilhar dois caminhos, de acordo com as modalidades do processo educativo, sendo encontrada em caráter Formal e Não-Formal. Entende-se por EA na educação escolar, com caráter Formal, aquela desenvolvida no âmbito dos currículos 
das instituições de ensino públicas e privadas (Art. $9^{\circ}$ ) e a EA Não-Formal como sendo as ações e práticas educativas voltadas à sensibilização da coletividade sobre as questões ambientais e à sua organização e participação na defesa da qualidade do meio ambiente (Art. 13º) (BRASIL, 1999).

Entre os aspectos vinculados à EA Não-Formal é apontado na lei, o incentivo a sensibilização da sociedade para a importância das Unidades de Conservação, a sensibilização ambiental das populações tradicionais ligadas a essas unidades, dos agricultores e também ao ecoturismo.

O ecoturismo é apontado como um segmento da atividade turística, o qual se apresenta como uma alternativa sustentável de exploração turística dos ambientes naturais (CASTRO et al., 2007).

Bueno e Pires (2006, p.15) afirmam que:

Há, de fato, a possibilidade do ecoturismo, juntamente com seu componente educativo (educação ambiental) propiciar a conservação da natureza, por meio de modalidades de educação ambiental (aprendizado sequencial, interpretação ambiental e educação experiencial), pois essas modalidades proporcionam a compreensão cognitiva dos benefícios de se conservar a natureza, estimulada por sentimentos acarretados pelas experiências diretas com a natureza.

A procura por áreas naturais pela população, seja para atividades recreativas, seja de educação, caracterizam a tentativa de reaproximação do homem com a natureza (TAKAHASHI, 2004). Essas áreas ficam suscetíveis aos impactos decorrentes da visitação, o que gera a necessidade de conciliar o uso recreativo e educativo com a conservação da natureza. É nesse contexto que se insere grande parte da EA NãoFormal, vinculada a um potencial educativo, por meio de um contato dirigido com a natureza (BUENO, 2010).

Os profissionais que desenvolvem trabalhos em EA encontram algumas dificuldades nesse processo de sensibilização porque cada indivíduo carrega consigo uma leitura ambiental própria, construída no decorrer de sua vida, "resultado das percepções (individuais e coletivas), dos processos cognitivos, julgamentos e expectativas de cada pessoa" (FERNANDES et al., 2003, p.1). A Percepção Ambiental é a função psicológica que caracteriza esse processo, "pode ser definida como sendo uma tomada de consciência do ambiente pelo homem, ou seja, o ato de perceber o ambiente que se está inserido, aprendendo a proteger e a cuidar do mesmo" (FERNANDES et al., 2003, p.1).

Del Rio e Oliveira (1996, p.3-22), quando se refere ao processo perceptivo (Figura 1), afirma que a mente humana organiza e representa a realidade percebida por meio de esquemas perceptivos e imagens mentais, com atributos específicos. 
Percepção ambiental dos usuários da fazenda Santa Branca Ecoturismo (APA - Ribeirão João Leite, GO).

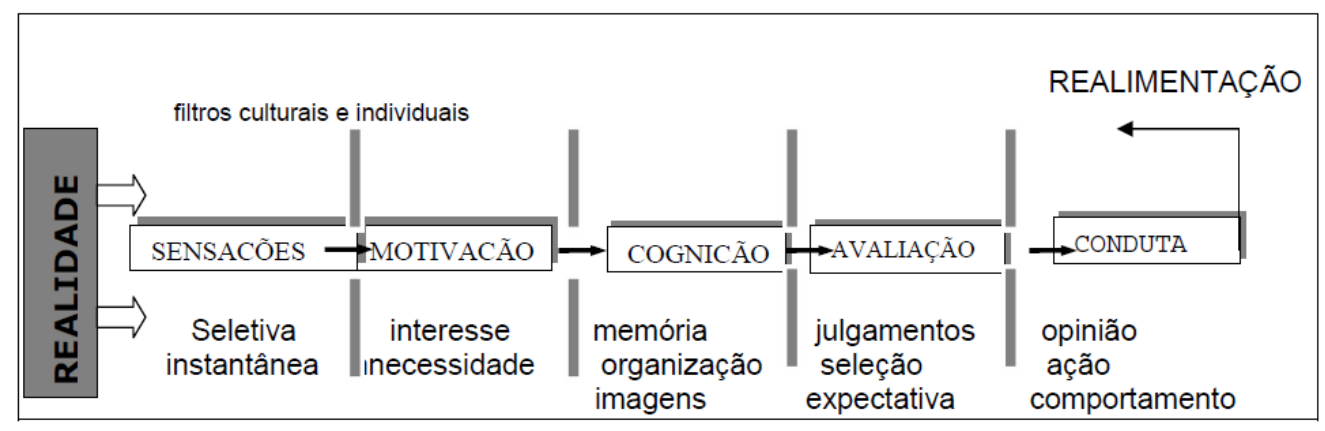

Figura 1 - Esquema Teórico do Processo Perceptivo. FONTE: Del Rio e Oliveira (1996)

De acordo com Capra (1996 apud SOARES, 2005), a crise ambiental resulta de uma crise de percepção, sendo urgente a reorientação nos modos de conhecer e se relacionar com a natureza. Deve-se, portanto, considerar as inter-relações existentes entre todos os seres e a biosfera, inclusive as estabelecidas pelo próprio homem, onde os esforços para conservar a biodiversidade, devem levar em consideração as preferências dos seres humanos que decidem o que conservar (STOKES, 2006).

Nessa perspectiva, estudos de percepção ambiental almejam uma compreensão das relações entre o ser humano e o ambiente, e conforme Soares (2005, p. 10)

(...) integram elementos da psicologia, geografia, biologia e antropologia, entre outras ciências, a principal finalidade é compreender os distintos comportamentos do ser humano em relação ao meio ambiente. As percepções revelam o modo como se vive e se planeja o espaço, é resposta das diferentes interações entre ser humano e meio ambiente.

A UNESCO (1973, p. 3-4), em um programa relacionado à percepção da qualidade ambiental, considera que a forma como as pessoas percebem o ambiente natural exerce uma grande influência em suas decisões sobre o próprio ambiente com qualidade de vida. Pondera também, que as diferentes percepções de valores e importância dos ecossistemas é um desafio a ser vencido pela EA.

Assim, estudos na área da Percepção Ambiental, envolvendo grupos que interferem num determinado ambiente e os impactos das atividades locais, despontam como ferramentas de grande importância para a elaboração de novas metodologias de EA e avaliação constante de trabalhos já implantados.

Nesse contexto, o objetivo do estudo foi avaliar as concepções de meio ambiente e a percepção ambiental dos usuários da Fazenda Santa Branca, em Teresópolis, GO, frente ao ambiente natural e ao trabalho de Educação Ambiental realizado na área, com base na aquisição e análise de informações de seu estado cognitivo. 


\section{Material e Métodos}

A Unidade Agroecológica Fazenda Santa Branca está situada a 40 km de Goiânia, Goiás, a $120 \mathrm{~km}$ de Brasília, Distrito Federal e a $20 \mathrm{~km}$ de Anápolis, Goiás. Está localizada na latitude $16^{\circ} 25^{\prime} 06^{\prime \prime}$ Sul e longitude $49^{\circ} 05^{\prime} 30^{\prime \prime}$ Oeste (Figura 2), em uma região onde predominam os últimos remanescentes de vegetação do chamado "Mato Grosso goiano". A Unidade, que possui 680 alqueires, dos quais 230 estão destinados a área de lazer, tem em seu interior sete nascentes, sendo cortada pelo Ribeirão João Leite, manancial de água potável que abastece a Capital Goiânia. A Unidade, de acordo com a legislação federal, é uma Reserva Particular do Patrimônio Natural (RPPN), e está localizada nos limites da Área de Proteção Ambiental (APA) da bacia do Ribeirão João Leite. No que concerne à definição dessas áreas dentro do "Sistema Nacional de Unidades de Conservação da Natureza (SNUC)", a lei 9985, de 18 de julho de 2000 conceitua em seus artigos:

Art. 15 - A Área de Proteção Ambiental é uma área em geral extensa, com um certo grau de ocupação humana, dotada de atributos abióticos, bióticos, estéticos ou culturais especialmente importantes para a qualidade de vida e o bem-estar das populações humanas, e tem como objetivos básicos proteger a diversidade biológica, disciplinar o processo de ocupação e assegurar a sustentabilidade do uso dos recursos naturais. Art. 21 - A Reserva Particular do Patrimônio Natural é uma área privada, gravada com perpetuidade, com o objetivo de conservar a diversidade biológica.

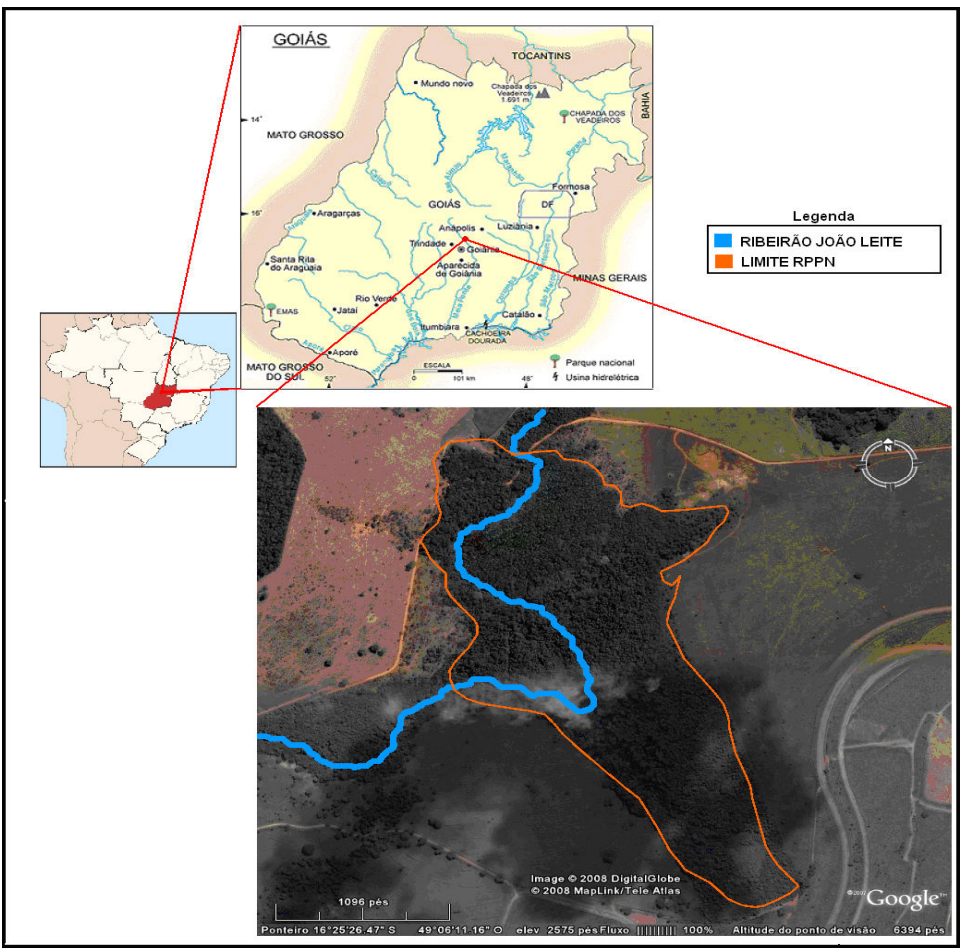

Figura 2 - Localização da Reserva Particular do Patrimônio Natural Fazenda Santa Branca, Teresópolis, GO. Fonte: http://maps.google.com.br/maps?hl=pt-BR\&tab=wl 
Percepção ambiental dos usuários da fazenda Santa Branca Ecoturismo (APA - Ribeirão João Leite, GO).

Entre as várias dimensões de atuação da Santa Branca, destaca-se a educação/pesquisa, produção agropecuária, ecovilas e o ecoturismo. No ecoturismo as atividades de EA são mais evidentes além de apresentar um grande fluxo de visitantes, que são o objeto de estudo da pesquisa. $O$ instrumento de coleta de dados utilizado foi o questionário estruturado aplicado a três diferentes públicos. Sua estruturação se deu à luz dos objetivos da pesquisa considerando também o tipo/nível dos entrevistados (FERNANDEZ et al., 2003). O questionário continha perguntas que possibilitaram avaliar as percepções dos diferentes públicos. Quanto aos assuntos abordados pelas perguntas de um questionário Ditt et al. (2006, p.618) afirma "(...) podem ser variados e sua escolha depende do que é encontrado na literatura e também da experiência e do conhecimento que o pesquisador possui das condições do objeto de estudo."

Os questionários vêm sendo utilizados em diversos campos de pesquisa com o objetivo de levantar a relação homem/ecossistema em prol da conservação, em função de apresentar simultaneamente uma eficiência na abordagem e coleta de informações e manter o anonimato do objeto de estudo (CALDAS, 2003, p. 141). Cunha et al. (2007) analisaram a percepção ambiental de moradores do entorno de uma Unidade de Conservação Municipal em Iporá - Goiás e por meio de um índice de consistência (Alfa de Cronbach), avaliaram a eficiência do questionário, concluindo que é possível fazer o levantamento do conhecimento ecológico de comunidades utilizando esse instrumento.

Três modelos de questionários foram elaborados visando a levantar o perfil e a percepção ambiental de cada público: visitantes, integrantes das atividades de EA e funcionários da fazenda Santa Branca. Para o estudo foram considerados visitantes os turistas que estivessem usufruindo das atividades oferecidas pela fazenda e que não fossem participantes dos grupos de EA.

No período de outubro a dezembro de 2008 foram aplicados 252 questionários por meio de abordagem direta e sistêmica dos usuários, sendo 185 direcionados para os visitantes, 30 para os integrantes das atividades de EA e 37 para os funcionários.

Para os integrantes das atividades de EA, a abordagem ocorreu após participarem das atividades educacionais, principalmente a trilha interpretativa. Para os demais, a amostragem foi feita em diferentes setores da fazenda, conforme ilustra a Figura 3.

A aplicação dos questionários foi precedida de uma explicação prévia do objetivo da pesquisa e do consentimento da participação voluntária. A tabulação dos dados foi realizada conforme Cunha e Zeni (2007, p.154):

As questões subjetivas foram tabuladas da seguinte maneira: as questões abertas (que geralmente apresentam respostas múltiplas) foram levantadas às palavras-chave e agrupadas de acordo com as respostas semelhantes e as questões fechadas foram agrupadas de acordo com a frequência das respostas. 


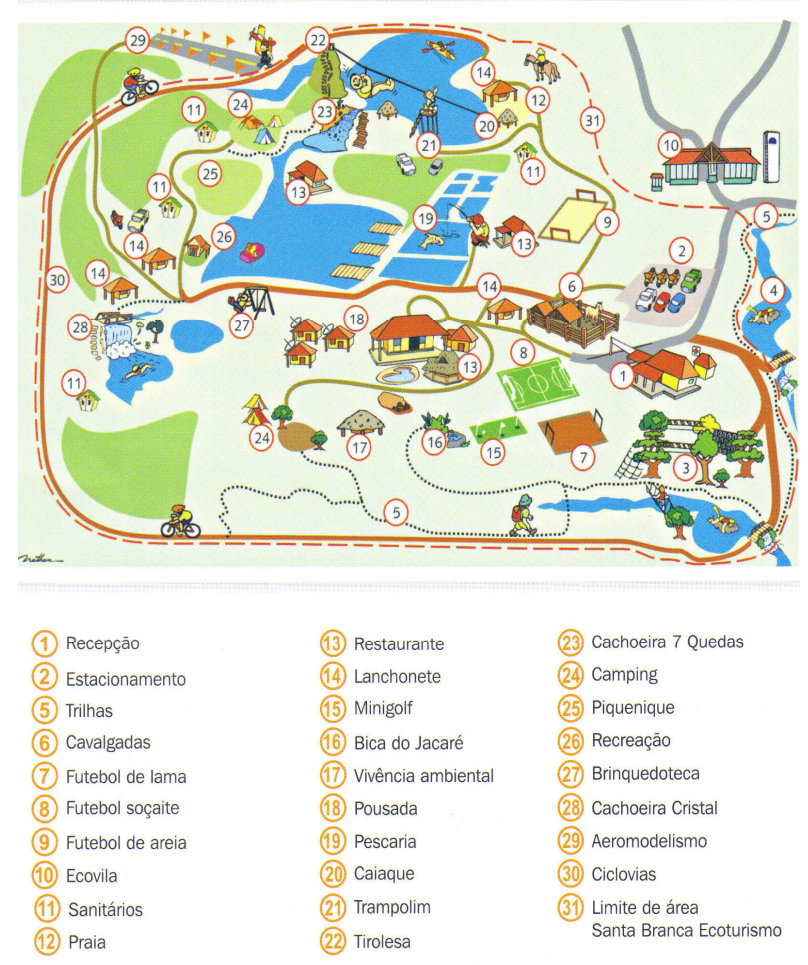

Figura 3 - Ilustração dos setores da Fazenda Santa Branca Ecoturismo, Teresópolis, GO. Fonte: Folder de divulgação da fazenda Santa Branca Ecoturismo (LTDA).

Adotou-se a divisão de classes socioeconômicas segundo o IBGE (2008): classe $A$ (acima de 30 salários mínimos), classe $B$ (de 15 a 30 salários mínimos), classe $C$ (de 6 a 15 salários mínimos), classe D (de 2 a 6 salários mínimos) e classe $\mathrm{E}$ (até 2 salários mínimos).

O fato de as variáveis serem categóricas levou à escolha de um teste nãoparamétrico, o Teste do $\mathrm{X}^{2}$ realizado com o auxílio do programa "ESTATISTICA 7.0". Testes não-paramétricos não exigem que a variável em análise seja numérica nem que existam pressuposições a respeito da distribuição dessa variável, e mesmo apresentando um "menor poder" quando comparados aos paramétricos, eles se mostram como alternativa para trabalhos com enfoque qualitativo que viole as pressuposições dos testes Paramétricos (VIEIRA, 2004, p.13).

\section{Resultados e Discussão}

Perfil Socioeconômico dos entrevistados

Em relação ao gênero dos visitantes, houve predominância do sexo masculino $(51,7 \%)$, o que ainda é comum em destinos de aventura, e de adultos, já que nessa categoria encontram-se os indivíduos economicamente ativos. A escolaridade predo- 
Percepção ambiental dos usuários da fazenda Santa Branca Ecoturismo (APA - Ribeirão João Leite, GO).

minante foi o ensino médio $(55,2 \%)$, seguido do ensino superior $(24,6 \%)$. Quanto à classe socioeconômica, o maior número de visitantes foi enquadrado nas classes $D$ e E, com respectivamente $41,3 \%$ e $36,5 \%$.

Dos integrantes das atividades de EA predominou o sexo feminino $(65,4 \%)$, crianças $(43,3 \%)$, o ensino fundamental $(46,7 \%)$, seguido pelo superior $(36,7 \%)$ e as classes D $(41,7 \%)$ e $E(58,3 \%)$. Na Unidade é comum a participação de grupos de escolares, o que justifica o alto percentual de crianças, já que as instituições de ensino da região têm recorrido ao local para a prática de atividades de EA.

O maior número de funcionários é adulto $(83,8 \%)$ e do sexo feminino $(76 \%)$. Quanto à escolaridade, predominaram os ensinos fundamental e médio (44,4\% cada), enquanto apenas $11,1 \%$ dos funcionários possuíam o ensino superior.

De modo geral, o baixo poder aquisitivo dos usuários pode estar relacionado ao baixo custo da "visita" quando comparado a outros destinos turísticos, a facilidade de acesso e à proximidade da área a grandes centros urbanos, tais como Goiânia e Anápolis (GO). O grau de escolaridade concorda com o nível socioeconômico da maioria dos entrevistados.

O planejamento de atividades e projetos de EA em ambiente Não-Formal tende a ser mais eficiente quando há um prévio conhecimento sobre o perfil do público que se pretende sensibilizar. "O conhecimento do público-alvo é fundamental para que se possa realizar uma comunicação eficiente, respeitando a cultura, a história de vida e a individualidade de cada um" (CUNHA e ZENI, 2007, p. 155).

\section{Expectativa dos Integrantes das atividades de EA e dos Visitantes}

Os visitantes e integrantes das atividades de EA responderam a perguntas sobre o que eles esperavam experimentar ao vir para a fazenda (Figura 4) e se a sua expectativa havia sido alcançada. Evidenciou-se uma maior disposição por parte dos integrantes das atividades de EA em visualizar e entender melhor um novo ambiente, principalmente entrar em contato com o natural (41,4\% natureza, $13,8 \%$ fauna, $10,3 \%$ emoção e 6,9 \% flora).

A alta frequência da categoria "natureza", tanto para os visitantes quanto para os integrantes das atividades de EA, ressalta a busca por aspectos abióticos diante do espaço geográfico. É possível aproveitando-se dessa prévia motivação, integrar o conhecimento geológicos à prática da Educação Ambiental, por meio da inserção de conhecimentos do meio físico, dentro de uma perspectiva de evolução dinâmica e histórica da natureza ao longo do tempo geológico, com abordagem interdisciplinar, despertando para o significado das múltiplas atividades humanas de utilização racional dos materiais geológicos e de ocupação e interferência no meio (BACCl, 2009). BriIha, Dias e Pereira (2006, p. 445) afirmam ainda que, "Sendo a Natureza constituída por elementos abióticos e bióticos, em muitos casos com grande interdependência, é imperioso que a Conservação da Natureza seja encarada numa perspectiva holística, 
integrando estratégias de conservação quer da geodiversidade como da biodiversidade."

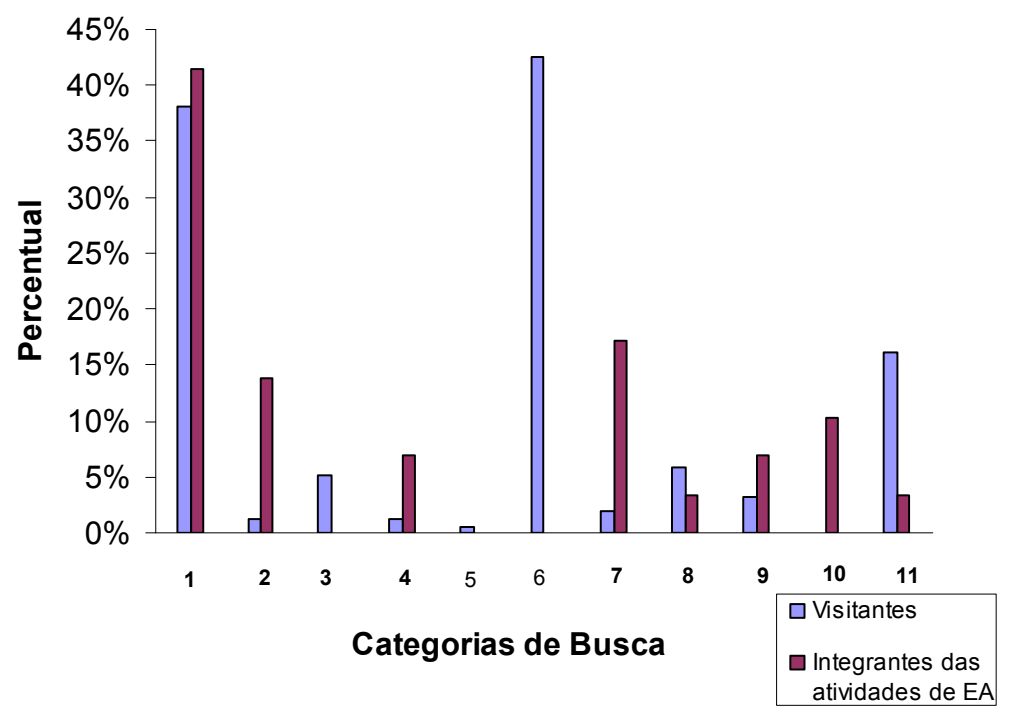

Figura 4 - Categorias de busca (1 Natureza, 2 Fauna, 3 Ecoturismo/atividades turísticas, 4 Flora, 5 Hospitalidade, 6 Descanso físico e mental, 7 Tudo, 8 Água, 9 Conhecimento, 10 Emoção, 11 Não Responderam) segundo as expectativas dos visitantes e integrantes das atividades de EA, a respeito do ambiente da fazenda Santa Branca Ecoturismo (2008).

Referente à biodiversidade é válido destacar que a busca por recursos da fauna é mais evidente que por recursos vegetais, observação também feita por Neiman, Cardoso-Leite e Podadera (2009, p. 24),

(...) aspectos como a composição e ecologia vegetal geralmente são pouco explorados em trilhas ou outros atrativos turísticos, talvez pela dificuldade em se reconhecer e identificar as espécies, ou pelo aspecto menos carismático que as plantas representam aos monitores e visitantes, comparando-se com a fauna, por exemplo, devido a uma percepção menos aguçada para este recurso.

Já os visitantes, além dessa busca por elementos naturais, relacionaram a fazenda com descanso físico e mental $(42,6 \%)$, com atividades de ecoturismo $(5,2 \%)$ e em um percentual menor, à hospitalidade $(0,6 \%)$. Esse anseio da população pelo retorno ao natural tem sido registrado em outros trabalhos realizados em parques (VAZ, 2010; TOMIAZI, VILLARINHO, 2005), demonstrando o bem estar proporcionado pelo 
Percepção ambiental dos usuários da fazenda Santa Branca Ecoturismo (APA - Ribeirão João Leite, GO).

apreciar a natureza e a busca do descanso em áreas naturais.

A maioria dos visitantes e integrantes das atividades de EA afirmou ter suas expectativas realizadas, resultado diferente do obtido por Caldas (2003), em que aproximadamente metade dos usuários do Parque Estadual da Serra de Caldas Novas (PESCAN) não teve satisfeitas suas expectativas. Naquele estudo, a aplicação dos questionários coincidiu com a baixa temporada de visitação do parque em função da estação seca, período no qual são encontrados poucos corpos d'água na área e vegetação predominantemente caducifólia, o que contraria a expectativa dos visitantes, já que o recurso hídrico e a vegetação foram fatores de busca importantes para os turistas e pesquisadores entrevistados no PESCAN. No presente estudo as expectativas dos visitantes e integrantes das atividades de EA provavelmente foram superadas em função da diversidade de atividades oferecidas na unidade, a exuberância da vegetação devido à época da realização do estudo, abundância de recursos hídricos e estrutura física (construída) para receber e atender satisfatoriamente às necessidades dos turistas.

\section{Estado de Conservação da Área}

Avaliou-se ainda, junto aos públicos pesquisados, o estado de conservação ambiental da Fazenda Santa Branca (Figura 5). As classificações "Bom" e "Ótimo" predominaram entre todos os grupos entrevistados, os quais não distinguiram os aspectos naturais das alterações antrópicas presentes nesse ambiente. Por isso a presença de estruturas artificiais (cachoeiras e lagos construídos, playground, bares, restaurantes, campo desmatado para camping etc.) não foi de encontro as suas expectativas pelo natural, nem mesmo as contrariou, demonstrando incapacidade perceptiva na presença dessas alterações ambientais, fator crítico principalmente no que se refere à manutenção de áreas de conservação.

Em síntese, os usuários sentem-se satisfeitos com o ambiente visitado, demonstrando que a antropização da área não é percebida como impacto negativo. A vivência nas cidades leva a uma perda da percepção dos impactos da antropização, ou seja, para muitos, esses impactos só são percebidos quando acontecem em grandes proporções. Neiman, Mendonça e Schlindwen (2008, p.124) justificam ainda que o mesmo ocorre porque no setor turístico "não há valorização das experiências autênticas de contato com o simples, com o rústico, mas simplesmente a imposição de roteiros em que a "convivência com a natureza" se dá com "todo conforto urbano".

Para os integrantes das atividades de EA, testou-se a hipótese de que a variável expectativa é independente da avaliação sobre o estado de conservação da área. $O$ resultado confirmou a hipótese testada $\left(X^{2}=7,6, G . L .=9, p=5 \%\right)$ e, portanto, não se pode afirmar, por exemplo, que os integrantes de EA (que esperam encontrar aspectos naturais) sejam mais sensíveis às alterações do ambiente natural. 


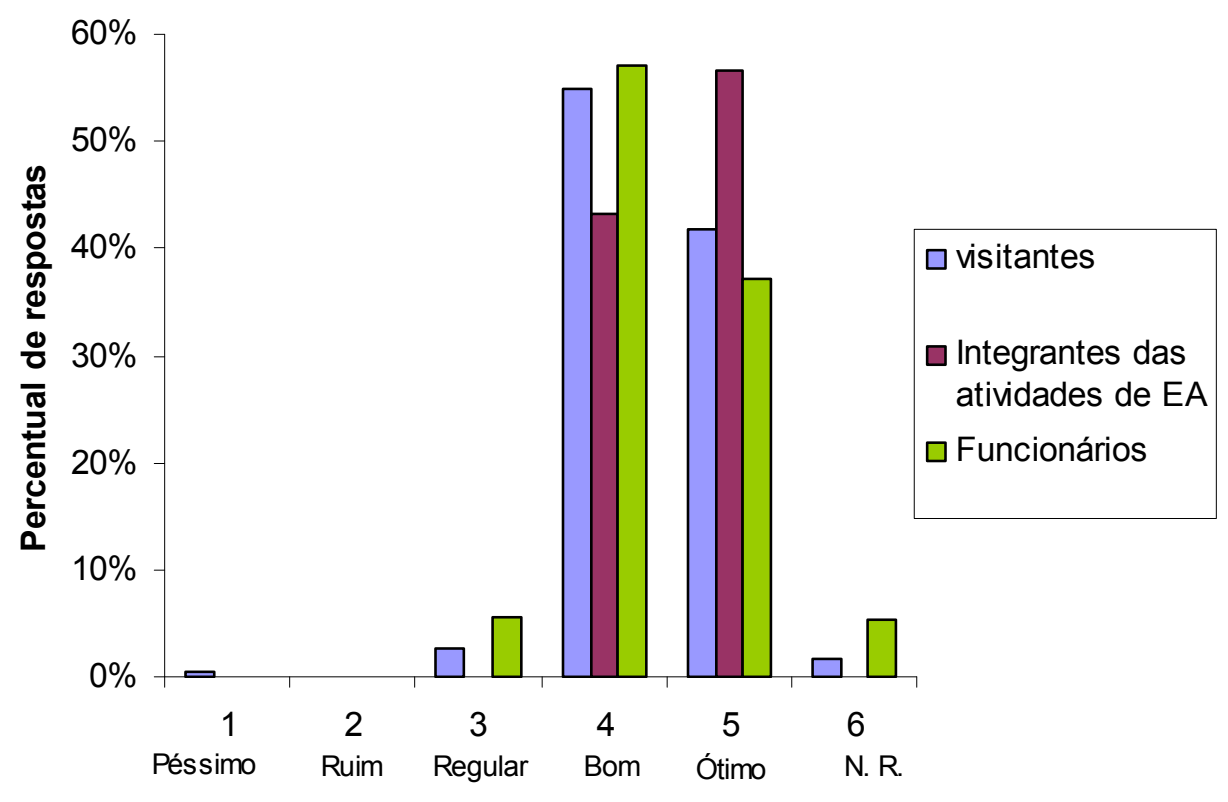

Figura 5 - Avaliação do estado de conservação da Unidade Santa Branca Ecoturismo segundo os usuários. N.R - Não Responderam.

Concepções de Meio Ambiente (MA)

As concepções dos usuários sobre meio ambiente são apresentadas na Tabela 1. Essas concepções foram organizadas sensu Reigota (1991) em: naturalista, na qual o meio ambiente é tido como sinônimo de natureza intocada, e onde evidenciamse somente os aspectos naturais; antropocêntrica voltada para a utilização dos recursos em função das necessidades do ser humano e globalizante, em que existem relações recíprocas entre natureza e sociedade.

Esses dados demonstram que a concepção naturalista predomina nos diferentes públicos. "Se o ambiente é representado pela natureza que se deve apreciar e respeitar, as estratégias educacionais deverão incluir atividades de imersão na natureza" (BEZERRA; GONÇALVES, 2007, p.119).

Seguida à concepção naturalista, a antropocêntrica foi detectada em $44,8 \%$ dos funcionários, $34,5 \%$ dos integrantes das atividades de EA e $32,7 \%$ dos visitantes. A concepção antropocêntrica permite fazer uma analogia a existência de paradigmas ainda dominantes tais como: o domínio sobre a natureza, objetivando o crescimento econômico, recursos naturais ilimitados, consumismo, entre outros. Os paradigmas se 
Percepção ambiental dos usuários da fazenda Santa Branca Ecoturismo (APA - Ribeirão João Leite, GO).

mantêm mesmo que uma nova ética já exija o abandono da perspectiva antropocêntrica para uma perspectiva mais global, biocêntrica (Globalizante) (DIEGUES, 1992).

Tabela 1 - Concepções de meio ambiente (sensu REIGOTA, 1991) dos usuários da Fazenda Santa Branca, Teresópolis/GO, 2008. (Os valores entre parênteses representam os percentuais de resposta respectivas a cada público).

\begin{tabular}{|c|c|c|}
\hline Concepção & Público & Depoimentos \\
\hline \multirow{3}{*}{ Naturalista } & Visitantes $(50,9 \%)$ & $\begin{array}{l}\text { "Todos os locais onde a natureza domi- } \\
\text { na onde as pessoas possam contem- } \\
\text { plá-la sem interferência." }\end{array}$ \\
\hline & $\begin{array}{c}\text { Integrantes de EA } \\
(44,9 \%)\end{array}$ & $\begin{array}{l}\text { "São todos os recursos naturais flora e } \\
\text { fauna que nos cercam." }\end{array}$ \\
\hline & Funcionários $(48,3 \%)$ & “É tudo aquilo que envolve a natureza." \\
\hline \multirow{3}{*}{ Antropocêntrica } & Visitantes $(32,7 \%)$ & $\begin{array}{l}\text { "Algo que para nossa sobrevivência } \\
\text { deve ser preservado." }\end{array}$ \\
\hline & $\begin{array}{c}\text { Integrantes de EA } \\
(34,5 \%)\end{array}$ & $\begin{array}{l}\text { "Eu entendo que sem o meio ambiente } \\
\text { nós não iríamos sobreviver então eu } \\
\text { ajudo a cuidar da natureza." }\end{array}$ \\
\hline & Funcionários $(44,8 \%)$ & $\begin{array}{l}\text { "É o meio de preservar o que a nature- } \\
\text { za nos deu." }\end{array}$ \\
\hline \multirow{3}{*}{ Globalizante } & Visitantes $(4,4 \%)$ & $\begin{array}{l}\text { "Meio ambiente é todo meio em que } \\
\text { vivemos, não só natureza como tam- } \\
\text { bém todo ambiente urbano." }\end{array}$ \\
\hline & Integrantes EA $(3,4 \%)$ & $\begin{array}{l}\text { "Entendo que é o meio onde co- } \\
\text { existimos e devemos cuidar." }\end{array}$ \\
\hline & Funcionários $(6,9 \%)$ & $\begin{array}{l}\text { "Começa com a gente é um sistema } \\
\text { interligado entre a vida e o viver das } \\
\text { pessoas." }\end{array}$ \\
\hline
\end{tabular}

O turismo pode conduzir os usuários a terem uma visão antropocêntrica e/ou naturalista, ao fazer do ambiente um produto, ou quando, na tentativa de valorizar, recorre a uma imagem de natureza intocada, conforme Neiman, Mendonça e Schlindwen (2008, p.116);

A experiência do meio ambiente como algo que se compra passa pela concepção de mercado, pois se o turista compra um pacote para visitar certo lugar, então aquele lugar é um produto, muitas vezes valorizado pela imaginação simbólica e tratado como "paradisíaco", "inesquecível" pelo marketing turístico. 
O baixo percentual de respostas com concepção globalizante foi encontrado em todos os públicos. Situação semelhante à encontrada por Bezerra, Feliciano e Alves (2008) em trabalho realizado sobre a percepção ambiental de alunos e professores do entorno da Estação Ecológica de Caetés em Recife (PE), o que demonstra um distanciamento da compreensão da complexidade ambiental.

As concepções dos entrevistados que não se enquadraram nas anteriores foram definidas como discrepantes, sendo encontradas em $12 \%$ dos visitantes e $17,2 \%$ dos integrantes de EA, como por exemplo, "o meio ambiente é inexplicável não se explica", "deve ser tratado igual um ser humano ele também é um ser" e "o meio ambiente ainda por ser um assunto muito discutido muitos não sabem seu valor (tudo)". Essas concepções confirmam a dificuldade que o público tem em definir o que é meio ambiente.

\section{Concepção de MA e a Educação}

A análise das variáveis evidenciou que a concepção de MA independe dos grupos de usuários $\left(X^{2}=4,9, G . L .=6, p=1 \%\right)$, portanto não existe uma dependência entre ter uma concepção globalizante e ter participado previamente das atividades de EA ou ser um funcionário da fazenda, o que detecta falhas na abordagem ambiental. As falhas conforme Pádua, Tabanez e Souza (2006, p.545) ocorrem por que:

$\mathrm{Na}$ ânsia de buscar o envolvimento de comunidades onde atuam, muitos pesquisadores desenvolvem atividades de educação ambiental deficientes em referenciais teóricos ou na sistematização das estratégias a serem adotadas. (...) A busca de eficácia é ainda mais reforçada diante da escassez de recursos alocados à educação e à falta de oportunidades de capacitação nessa área.

As concepções de meio ambiente também independem da escolaridade $\left(X^{2}=7,6, G . L .=9, p=1 \%\right)$, evidenciando falhas nos níveis formais de ensino. Sobre a precariedade da EA na prática docente, Viana e Oliveira (2006) afirmam que "esse fato se deve a vários aspectos, tanto sociais, culturais, pedagógicos, e principalmente, pela carência de pessoal qualificado, aliado à inexistência de metodologia e material apropriado ao tratamento do tema". Essas mesmas justificativas podem ser transpostas para a EA Não Formal.

Dentre as ferramentas para se trabalhar com EA Não Formal é válido destacar as trilhas interpretativas, devido a sua facilidade em promover uma inserção ao natural, porém, assim como na EA Formal, deve-se atentar para a carência de monitores qualificados e de uma constante avaliação dos métodos de trabalho. Salgado e Sabino (2006, apud NEIMAN; CARDOSO-LEITE; PODADERA, 2009, p.14) afirmam que: 
Percepção ambiental dos usuários da fazenda Santa Branca Ecoturismo (APA - Ribeirão João Leite, GO).

(...) para facilitar o processo de utilização dos recursos naturais, uma das possibilidades é a realização de programas de capacitação para condução de pessoas em trilhas, o que possibilitaria o seu uso de forma racional, introduzindo conceitos e práticas sustentáveis.

Neiman (2007) ressalta o papel dos monitores ambientais em fazer com que turistas percebam melhor o ambiente visitado, fato que poderia modificar o comportamento pós-visitação com a construção de atitudes a favor da conservação ambiental.

Obstáculos encontrados para execução tanto da EA Formal quanto Não Formal podem ser justificados pelo histórico brasileiro, pois segundo Pedrini e Brito (2006, p.4) "A educação ambiental no Brasil não traçou um caminho linear, pois passou e vem passando muitos percalços para sua implantação e desenvolvimento no ensino formal, não-formal e informal".

O saber sobre essas questões, referentes à percepção ambiental, é de fundamental importância frente às necessidades de uma EA condizente, que propicie uma desestabilização construtiva das concepções, aproximando mais os aspectos educativos à conservação ambiental.

\section{Conclusão}

Conclui-se que a concepção de MA independe dos grupos de usuários pesquisados. Esse fato remete à reflexão sobre a capacidade de sensibilização dos projetos de EA desenvolvidos em Unidades de Conservação (UCs). Como exemplo, podemos citar o presente estudo, no qual os resultados foram encaminhados aos responsáveis pelo projeto de Educação Ambiental desenvolvido na área, objetivando à autoavaliação.

Evidenciou-se que existe, entre os visitantes, o desejo de estar em contato com a natureza, no entanto, as experiências ambientais vivenciadas durante a realização das atividades de EA não instigaram a formulação de uma nova percepção, mais globalizante, nem inseriram, conforme sugere Couto (2009), conceitos científicos básicos essenciais para tomada de posição frente às pressões antrópicas aos ecossistemas.

É possível afirmar ainda, que existe na área pesquisada, a necessidade de capacitar os funcionários, com destaque para os guias, já que na posição de educadores são eles que irão conduzir efetivamente o aprendizado no decorrer das atividades, constituindo-se, portanto, em ferramentas diretas entre a paisagem e a percepção construída pelo grupo.

Sugere-se, tanto para a Unidade Santa Branca Ecoturismo, como para outras UCs, a realização de pesquisas complementares a essa, que foquem os aspectos da população e da parte agroecológica do local, por meio de uma abordagem participativa, que segundo Pádua, Tabanez e Souza (2006) instiga a população do entorno e a que utiliza as áreas naturais a se envolverem com a conservação, ajudando a protegê-la.

Existe um grande potencial educativo nas atividades de EA em UCs, devido ao próprio espaço geográfico e à existência de um público específico de visitantes dis- 
Sousa, R.G,; Santos, M.L..

posto a visualizar e entender melhor um novo ambiente. A importância dessa e de outras pesquisas, que objetivam diagnosticar a percepção ambiental, está no esclarecimento da conduta do homem em relação à natureza e as atividades turísticas, buscando otimizar esse potencial educativo em prol da conservação.

\section{Referências Bibliográficas}

BACCI, D. L. C. A contribuição do conhecimento geológico para a educação ambiental. Pesquisa em debate. Ed. 11, v. 6, n. 2, jul/dez. 2009.

BEZERRA, T. M. O.; GONÇALVES, A. A. C. Concepções de meio ambiente e educação ambiental por professores da Escola Agrotécnica Federal de Vitória de Santo Antão-PE. Biotemas, n. 20, p. 115-125, setembro de 2007.

BEZERRA, T. M. O.; FELICIANO, A. L. P.; ALVES, A.G.C. Percepção ambiental de alunos e professores do entorno da Estação Ecológica de Caetés: Região Metropolitana do Recife-PE. Biotemas, n. 21, p. 147-160, março de 2008.

BRASIL. Lei federal $n^{\circ}$ 9985, de 18 de junho de 2000. Regulamenta o artigo 225, $\S 1^{\circ}$, incisos I, II, III e VII da Constituição Federal, institui o Sistema Nacional de Unidades de Conservação da Natureza e dá outras providências. Disponível em: <http:// www..socioambiental.org/website/noticias/naintegra/docs/snuc.html>. Acesso em: $10 \mathrm{de}$ maio de 2010.

BRASIL. O Programa Nacional de Educação Ambiental (ProNEA). Brasília, MMA/DEA, 3 ed., 2005, 5 p.

BRASIL. Decreto lei $n^{\circ}$ 9795, de 27 de abril de 1999. Dispõe sobre a educação ambiental, institui a Política Nacional de Educação Ambiental e dá outras providências. Brasília, abril 1999. Disponível em: http://www.planalto.gov.br/ccivil/Leis/L9795.htm Acesso em: junho de 2008.

BRILHA, J.; DIAS, G.; PEREIRA, D.; A geoconservação e o ensino/aprendizagem da geologia. In: Simpósio Ibérico do ensino da geologia/ XIV Simpósio sobre ensenanza da La geologia/ XXVI Curso de Actualização de professores de geociências, 2006, Portugal. Livro de Acta. Portugal: Universidade de Aveiro, p. 445 - 448, 2006.

BUENO, F. P.; PIRES, P. S. Ecoturismo e educação ambiental: possibilidades e potencialidades de conservação da natureza. In: Seminário de pesquisa em turismo do MERCOSUL, 2006, Caxias do Sul-RS. Anais. Caxias do Sul: Universidade de Caxias do Sul, p. 118, 2006.

BUENO, F. P. Vivências com a natureza: uma proposta de Educação Ambiental para o uso público em Unidades de Conservação. Revista Brasileira de Ecoturismo. São Paulo, v.3, n.1, pp. 61-78, 2010. Disponível em: http://www.sbecotur.org.br/rbecotur/artigos/ artigo19.pdf Acesso em: 8 de novembro de 2009.

CALDAS, A. L. R. Percepção Ambiental dos usuários do Parque Estadual da Serra de Caldas Novas - Goiás com relação à sua inserção no Meio Ambiente. Métodos de Campo em Ecologia. Brasília, p. 140-150, 2003. 
Percepção ambiental dos usuários da fazenda Santa Branca Ecoturismo (APA - Ribeirão João Leite, GO).

CASTRO, J.F.; FARIA, H.H.; PIRES, A.S.; OLIVIER, S.D. O Perfil dos Visitantes do Parque Estadual do Morro do Diabo, Estado de São Paulo. In: Congresso Nacional de Ecoturismo, 2007, Itatiaia, Anais ... Itatiaia, out. 2007, p.113-116. Disponível em: http:// www.physis.org.br/ecouc/Artigos/Artigo41.pdf Acesso em: 10 de maio de 2010.

COUTO, R. S. Percepção ambiental dos visitantes do Parque natural municipal Atalaia. In: IX CONGRESSO DE ECOLOGIA DO BRASIL, 2009, São Lourenço. Anais... São Lourenço:UENF. Disponível em: http://www.sebecologia.org.br/2009/ trabalhos ixceb humana.html Acesso em: janeiro 2009.

CUNHA, T. S.; ZENI, A. L. B. Representação social de meio ambiente para alunos de ciências e biologia: subsídio para atividades em Educação Ambiental. Revista Eletrônica do Mestrado em Educação Ambiental. v. 18, janeiro a junho de 2007. Disponível em: < http://www.remea.furg.br/> Acesso em: agosto de 2008.

CUNHA, H. F.; VALE, M.S.; JUNIOR, C.A.S.;CAMPOS,R.F.;CARLOS, L.O. Conhecimento empírico dos moradores da comunidade do entorno do Parque Municipal da Cachoeirinha (Iporá-Goiás) Acta Sci. Biol. Sci. Maringá, v. 29, n. 2, p. 203-212, 2007.

DEL RIO, Vicente; OLIVEIRA, Lívia (orgs.). Percepção Ambiental: A Experiência Brasileira, São Carlos: Editora da UFSCar, 1996, 265p.

DIEGUES, A. C. S. Desenvolvimento Sustentável ou Sociedades Sustentáveis: da crítica dos modelos aos novos paradigmas. São Paulo em Perspectiva, São Paulo, n. 6, p. 2229, jan/jun 1992.

DITT, E.H. et al. Entrevistas e aplicação de questionários em trabalhos de conservação. In: CULLEN JR, L. et al. (Org.). Métodos de estudo em biologia da conservação e manejo da vida silvestre, Curitiba: ed. da UFPR, 2003, p. 631-646.

FERNANDES, R. S. et al. Uso da Percepção Ambiental como Instrumento de Gestão em Aplicações Ligadas às Áreas Educacional, Social e Ambiental. Núcleo de Estudo em Percepção Ambiental-NEPA, Espírito Santo, 2003.

INSTITUTO BRASILEIRO DE GEOGRAFIA E ESTATISTICA, 2008. Dados de classes sócio-econômicas. Disponível em: <http://www.ibge.gov.br/home/>. Acesso em: agosto de 2008.

LINDBERG, K.; HAWKINS, D. E. Ecoturismo: Um Guia para Planejamento e Gestão. 2. ed. São Paulo: SENAC, 1999.

LOBO, H. A. S. Ecoturismo e percepção de impactos socioambientais sob a ótica dos turistas no Parque estadual turístico do Alto Ribeira - PETAR. Pesquisa em turismo e paisagens Cársticas. v.1, n.1, p. 67-75, 2008.

LUCION, A. P. S. et al. Desenvolvimento Sustentável. Biotecnologia Ciência e Desenvolvimento, Rio Grande do Sul, n. 36, p. 70-77, janeiro/junho 2006. 
Sousa, R.G,; Santos, M.L..

NEIMAN, Z. A educação ambiental através do contato dirigido com a natureza. São Paulo: Tese (Doutorado em Psicologia Experimental), Universidade de São Paulo. 2007.

NEIMAN, Z.; CARDOSO-LEITE, E.; PODADERA, D.S. Planejamento e implantação participativos de programas de interpretação em trilhas na "RPPN Paiol Maria". Revista Brasileira de Ecoturismo. São Paulo, v.2, n.1, p.11-34, 2009. Disponível em http:// www.physis.org.br/seer/index.php/ecoturismo/issue/view/2/showToc Acesso em: 8 de novembro de 2009.

NEIMAN, Z.; MENDONÇA, V. M.; SCHLINDWEN, M. N. Eu e a Brisa: reflexões sobre a experiência da viagem no turismo. Revista Brasileira de Ecoturismo. São Paulo, v. 1, n. 1, PP. 114-135, 2008. Disponível em: < http://www.physis.org.br/seer/index.php/ ecoturismo/issue/view/2/showToc > Acesso em: 8 de novembro de 2009.

PADUA, S. M.; TABANEZ, M. F.; SOUZA, M. G. A abordagem participativa na educação para a conservação da natureza. In: PADUA, C. V.; CULLEN, L. J.; RUDRAN, R. (Org.). Métodos de Estudo em Biologia da Conservação Manejo da Vida Silvestre. 2. ed. Curitiba:EdUFPR, 2006. p. 543.

PEDRINE, A. G; BRITO, M. I. M. Educação ambiental para o desenvolvimento ou sociedades sustentável? Uma breve reflexão para a América latina. Revista (virtual) Educação Ambiental em Ação, v. 17, 20 p., 2006.

REIGOTA, M. . O que é educação ambiental. São Paulo: Brasiliense, 1991. 63pp.

SOARES, S. M. V. A percepção ambiental da população Noronhense em relação à área de preservação ambiental. 2005. 96 f. Monografia (Pós-Graduação em Gestão e Política Ambiental do Departamento de Letras e Ciências Humanas) - Universidade Federal Rural de Pernambuco, Pernambuco, 2005.

STOKES, D. Things We Like: Human Preferences among Similar Organisms and Implications for Conservation. Human Ecology, Washington, USA, v.35, p.361-369, 2006.

TAKAHASHI, L.Y. Uso público em Unidades de Conservação. Cadernos de conservação, Curitiba, v.2, n.2, 2004. 40 p.

TOMIAZI, A.B.; VILLARINHO, F.M. Perfil dos Visitantes do Parque Natural Municipal do Mendanha, Município do Rio de Janeiro (RJ). 2005. Tese (Doutorado em Ciências Florestais), Universidade Federal de Lavras, Lavras, 2005.

UNESCO. Man and the Biosphere Programme (MAB). Expert Panel of Project 13: "Perception of Environmental Quality". Paris/França, 26-29 de março de 1973. Disponível em <http://unesdoc.unesco.org/images/0000/000032/003216eb.pdf>. Acesso em 10 de maio de 2010.

VAZ, D. M. S. Perfil dos visitantes do Parque Natural Municipal do Açude da Concórdia - Valença (RJ). Revista Brasileira de Ecoturismo. São Paulo, v. 3, n.1, pp.109120, 2010. Disponível em: http://www.physis.org.br/seer/index.php/ecoturismo/article/ viewFile/59/32 Acesso em: 8 de novembro de 2009. 
Percepção ambiental dos usuários da fazenda Santa Branca Ecoturismo (APA - Ribeirão João Leite, GO).

VIANA,P. A. M. O.; OLIVEIRA, J. E. A inclusão do tema meio ambiente nos currículos escolares. Revista Eletrônica do Mestrado em Educação Ambiental, Rio Grande RS, v. 16, p 1-17, jan/jun. 2006.

VIEIRA, S. Bioestatística: Tópicos avançados. 2 ed. Rio de Janeiro: Campus, 2004. $216 p$.

WWF BRASIL. 500 anos de destruição ambiental no Brasil: Um balanço do meio ambiente. Brasília: WWF Brasil, 2000. 24 p.

\section{Agradecimentos}

A Unidade Agroecológica Santa Branca Ecoturismo pela autorização para realização da presente pesquisa.

\section{Informações técnicas}

O resumo desta pesquisa já foi apresentado no IX Congresso de Ecologia do Brasil em 2009, na cidade de São Lourenço, MG.

Raquel Gonçalves de Sousa: Universidade Estadual de Goiás.

Email: kel_uegbio@yahoo.com.br

Link para o currículo Lattes: http://lattes.cnpq.br/8634125106707602

Mirley Luciene dos Santos: Universidade Estadual de Goiás.

Email: mirley.santos@ueg.br

Link para o currículo Lattes: http://lattes.cnpq.br/4037739389334742

Data de submissão: 28 de fevereiro de 2010.

Data do aceite: 17 de maio de 2010. 